\title{
Uterovaginal prolapse: The sociodemographic profile and reproductive health service uptake in A Low Resource Setting, Calabar, Nigeria
}

\author{
Charles Obinna Njoku, a,b Amarachukwu Nnaemezie Njoku, Efiok Eyo Efiok ${ }^{a, b}$
}

${ }^{a}$ Department of Obstetrics and Gynecology, University of Calabar, Calabar, Nigeria.

${ }^{b}$ Department of Obstetrics and Gynecology, University of Calabar Teaching Hospital, Calabar, Nigeria.

Correspondence to: Njoku Charles (email: charlesnjokuobinna@gmail.com).

(Submitted: 09 September 2019 - Revised version received: 04 October 2019 - Accepted: 12 October 2019 - Published online: 26 February 2020)

\begin{abstract}
Objective To determine the prevalence, sociodemographic profiles, utilization of reproductive health services, and delay in seeking medical care of patient with uterovaginal prolapse in Calabar, Nigeria.

Methods This was a retrospective study of women who presented with uterovaginal prolapse at University of Calabar Teaching Hospital, Calabar, Nigeria between May 1, 2009 and June 1, 2019. Patients' case records were retrieved and analyzed. Statistical analysis was done using SPSS Version 22.

Results The prevalence of genital prolapse was $0.3 \%$. The mean age and parity were $60.19 \pm 8.71$ years and $6.31 \pm 2.80$, respectively. The mean duration of symptoms before presentation was $3.19 \pm 2.16$ years. Genital prolapse was commonest among age group 60-79 years (52.8\%), parity 5-9 (66.7\%), post-menopausal (97.2\%), primary education (55.6\%), and farmers (47.2\%). Grade 3 uterovaginal prolapse was the commonest grade (58.3\%). Most patients (86.1\%) had symptoms of genital prolapse for less than 5 years before seeking medical treatment. The majority of patients had no antenatal care during their pregnancies (80.6\%), no skilled attendant at deliveries (86.1\%), and no contraceptive use during their reproductive years (77.8\%). Participants with lower parity (1-4) $(p=0.03)$, higher educational level $(p<0.001)$, and teachers/civil servants $(p=0.043)$ presented earlier ( $<1$ year) to the hospital.

Conclusion There is poor utilization of reproductive health services among women who develop uterovaginal prolapse in our environment. Women with higher social status sought for help earlier. Increasing awareness of this condition and providing antenatal care, skilled birth attendants, and contraceptive services will reduce the burden of this condition.

Keywords uterovaginal prolapse, reproductive health services, delayed presentation.
\end{abstract}

\section{Introduction}

Uterovaginal prolapse is a common gynecological condition particularly in the grandmultipara. ${ }^{1-3}$ It is of importance to gynecologist in the developing and low resource countries as women in these environments are predisposed to genital prolapse due to repeated child birth, low-skilled attendant at delivery, and low contraceptive usage. ${ }^{1-4}$ It has a prevalence of $41-50 \%$ in women over the age of 40 years, with a lifetime risk of $7 \% .{ }^{5}$ However, the prevalence is difficult to determine in low resource environment as most of the women do not seek medical attention unless symptoms are pronounced and disturbing. ${ }^{6}$

The female genital organs are maintained in their normal anatomical position by a number of fascial condensations (endopelvic fascia) such as the transverse cervical (cardinal) and uterosacral ligaments. ${ }^{6}$ Genital prolapse occurs as a result of weakness of these supportive structures. Risk factors for genital prolapse include repeated deliveries, difficult vaginal deliveries, increase intra-abdominal pressure, and estrogen withdrawal as in post-menopausal women. ${ }^{7-9}$

Three degrees of uterovaginal prolapse are described and the level of the cervix (the lowest and dependent part) is assessed while the patient is straining. First-degree prolapse is when the descent is still within the vagina; second degree when it has reached the introitus and third degree when it has gone beyond the introitus. The third degree, termed procidentia, is usually accompanied by cystourethrocoele and rectocoele. ${ }^{2}$

Previous surveys have studied the prevalence, risk factors, and management of uterovaginal prolapse; however, there is paucity of information on utilization of reproductive health services and health-seeking behavior of patients with genital prolapse. ${ }^{1-4,10,11}$ This information is important, especially in low resource environment, as it gives insight on underlying factors that may predispose patients to this condition and behavior that promotes it. This will form basis for formulation of preventive strategies. Therefore, this study was designed to determine the prevalence, sociodemographic characteristics, utilization of reproductive health services, and health-seeking attitude of patients with uterovaginal prolapse in University of Calabar Teaching Hospital, south-south, Nigeria.

\section{Methods and Materials}

This was a retrospective descriptive study of women who presented with genital prolapse in University of Calabar Teaching Hospital over a 10-year period from May 1, 2009 to June 1, 2019. Data of patient diagnosed with genital prolapse within this period were collected from registers in the gynecological clinic, gynecological ward, gynecological theatre, and from patients' case records in the medical record department. Data obtained included age, parity, menopausal status, occupation, marital status, grade of prolapse, duration of prolapse before presentation, history of antenatal care, history of skilled attendant at previous deliveries, and history of contraceptive use. SPSS Statistics (IBM Corp. version 22) program was used for data analysis.

\section{Results}

During the period studied, of the 15,543 new gynecological clinic attendees 45 patients were diagnosed with 
genital prolapse, giving a prevalence of $0.3 \%$. However, 39 case records were retrieved of which 36 had adequate information for analysis. The mean age and parity were $60.19 \pm 8.71$ years and $6.31 \pm 2.80$, respectively. The mean duration of symptoms before presentation was $3.19 \pm 2.16$ years. Sociodemographic features of patients are shown in Table 1. Genital prolapse was commonest among age group 60-79 years (52.8\%), followed by $40-59$ years $(44.4 \%)$. The modal parity was $5-9$ (66.7\%). Majority (97.2\%) of the patients were post-menopausal, $55.6 \%$ had primary education, $47.2 \%$ were farmers, and $94.4 \%$ were married. Grade 3 uterovaginal prolapse was the commonest grade (58.3\%) and Grade 2 was the second commonest $(38.9 \%)$ while Grade 1 was the least $(2.8 \%)$ as shown in Fig. 1.

Table 2 shows the duration of symptoms before seeking care and usage of reproductive health services of patients. The commonest duration of symptoms before seeking medical treatment was 2 years and below (44.4\%), followed by $3-4$ years $(36.1 \%)$, and the least was 7 years and above

Table 1. Sociodemographic features of participants.

\begin{tabular}{|c|c|c|}
\hline Variables & Frequency & Percentage (\%) \\
\hline \multicolumn{3}{|l|}{ Age (years) } \\
\hline $40-59$ & 16 & 44.4 \\
\hline $60-79$ & 19 & 52.8 \\
\hline$>80$ & 1 & 2.8 \\
\hline \multicolumn{3}{|l|}{ Parity } \\
\hline $1-4$ & 9 & 25 \\
\hline $5-9$ & 24 & 66.7 \\
\hline$>10$ & 3 & 8.3 \\
\hline \multicolumn{3}{|l|}{ Menopausal status } \\
\hline Post-menopause & 35 & 97.2 \\
\hline Pre-menopause & 1 & 2.8 \\
\hline \multicolumn{3}{|l|}{ Education level } \\
\hline No formal education & 9 & 25 \\
\hline Primary & 20 & 55.6 \\
\hline Secondary & 4 & 11.1 \\
\hline Tertiary & 3 & 8.3 \\
\hline \multicolumn{3}{|l|}{ Occupation } \\
\hline Farmer & 17 & 47.2 \\
\hline Trader & 11 & 30.6 \\
\hline Housewife & 4 & 11.1 \\
\hline Teacher & 3 & 8.3 \\
\hline Civil servant & 1 & 2.8 \\
\hline \multicolumn{3}{|l|}{ Marital status } \\
\hline Married & 34 & 94.4 \\
\hline Single & 2 & 5.6 \\
\hline
\end{tabular}

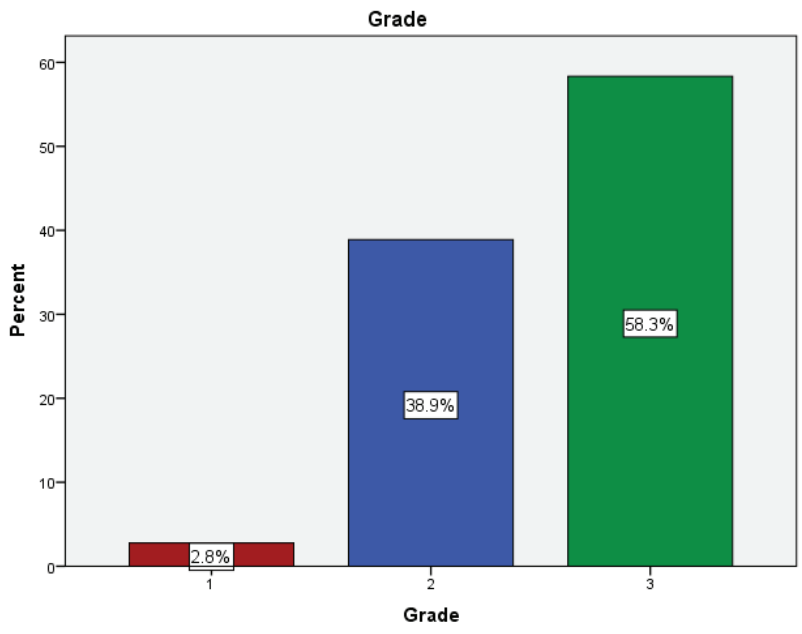

Fig. 1 Grade of genital prolapse among participants.

\begin{tabular}{|c|c|c|}
\hline Variables & Frequency & Percentage (\%) \\
\hline \multicolumn{3}{|c|}{ Duration of symptom before presentation (years) } \\
\hline \multicolumn{3}{|l|}{$\leq 2$} \\
\hline $3-4$ & 16 & 44.4 \\
\hline $5-6$ & 13 & 36.1 \\
\hline \multirow[t]{2}{*}{$\geq 7$} & 4 & 11.1 \\
\hline & 3 & 8.3 \\
\hline \multicolumn{3}{|c|}{ Antenatal care in previous deliveries } \\
\hline \multicolumn{3}{|l|}{ Yes } \\
\hline \multirow[t]{2}{*}{ No } & 7 & 19.4 \\
\hline & 29 & 80.6 \\
\hline \multicolumn{3}{|c|}{ Skilled attendant at deliveries } \\
\hline Yes & 5 & 13.9 \\
\hline No & 31 & 86.1 \\
\hline \multicolumn{3}{|c|}{ History of contraceptive use } \\
\hline Yes & 8 & 22.2 \\
\hline No & 28 & 77.8 \\
\hline
\end{tabular}

(8.3\%). The majority of patient had no antenatal care during their pregnancies $(80.6 \%)$, no skilled attendants at deliveries (86.1\%), and did not use contraceptive during their reproductive years $(77.8 \%)$. The relationship between delay in seeking medical care and sociodemographic characteristics of patients is shown in Table 3. Higher proportion (66.7\%) of participants with lower parity (1-4) presented earlier $(<1$ year) compared to participants with higher parity and the difference is statistically significant $(\mathrm{p}=0.03)$. Participants with tertiary $(66.7 \%)$ and secondary education $(100 \%)$ presented earlier $(<1$ year) than those with lower educational level $(\mathrm{p}<0.001)$. Teachers $(100 \%)$ and civil servants $(66.7 \%)$ sought help earlier $(<1$ year $)$ than farmers, traders, and housewives $(\mathrm{p}=0.043)$. 


\begin{tabular}{|c|c|c|c|c|}
\hline \multirow[b]{2}{*}{ Variables } & \multirow[b]{2}{*}{ Total } & \multicolumn{2}{|c|}{ Duration of symptom } & \multirow[b]{2}{*}{$p$-value } \\
\hline & & $\begin{array}{l}1 \text { year and } \\
\text { below }(\%)\end{array}$ & $\begin{array}{c}\text { Above } \\
1 \text { year (\%) }\end{array}$ & \\
\hline \multicolumn{5}{|l|}{ Age (years) } \\
\hline $40-59$ & 16 & $7(43.8)$ & $9(56.2)$ & $X^{2}=5.456$ \\
\hline 60-79 years & 19 & $2(10.5)$ & $7(89.5)$ & $D f=2$ \\
\hline$>80$ years & 1 & $0(0.0)$ & $1(100.0)$ & $P$ value $=0.065$ \\
\hline \multicolumn{5}{|l|}{ Parity } \\
\hline $1-4$ & 9 & $6(66.7)$ & $3(33.3)$ & $X^{2}=11.333$ \\
\hline $5-9$ & 24 & $3(12.5)$ & $21(87.5)$ & $D f=2$ \\
\hline$>10$ & 3 & $0(0.0)$ & $3(100.0)$ & $P$ value $=0.03^{*}$ \\
\hline \multicolumn{5}{|c|}{ Education level } \\
\hline $\begin{array}{l}\text { No formal } \\
\text { education }\end{array}$ & 9 & $0(0.0)$ & $9(100.0)$ & \\
\hline Primary & 20 & $3(15.0)$ & 17(85.0) & $X^{2}=18.844$ \\
\hline Secondary & 4 & $4(100.0)$ & $0(0.0)$ & $D f=3$ \\
\hline Tertiary & 3 & $2(66.7)$ & $1(33.3)$ & $P$ value $<0.001^{*}$ \\
\hline \multicolumn{5}{|l|}{ Occupation } \\
\hline Farmer & 17 & $1(5.9)$ & 16(94.1) & \\
\hline Trader & 11 & $4(36.4)$ & $7(63.6)$ & $X^{2}=9.849$ \\
\hline Housewife & 4 & $1(25.0)$ & $3(75.0)$ & $D f=4$ \\
\hline Teacher & 3 & $2(66.7)$ & $1(33.3)$ & $P$ value $=0.043^{*}$ \\
\hline Civil servant & 1 & $1(100.0)$ & $0(0.0)$ & \\
\hline
\end{tabular}

\section{Discussion}

The prevalence of uterovaginal prolapse among gynecological clinic attendees in this study was $0.3 \%$. This was comparable to $0.8 \%$ of gynecological clinic attendees south-south Nigeria, but lower than 3.9\% of gynecological admissions in south-east Nigeria, and $1.4 \%$ of gynecological admissions in northern Nigeria. ${ }^{1,2,4}$ The prevalence of genital prolapse in this study may not be the true representation of the burden of the condition as this is a hospital-based study. Moreover, social and economic barriers that may preclude hospital presentation are highly prevalent in our environment. There is need for community-based study in order to ascertain the actual burden of genital prolapse in this environment. This will help to plan effective preventive strategies.

The mean age for genital prolapse in this study was $60.19 \pm 8.71$ years, with the modal age being $60-79$ years. Similar findings were reported from previous studies. ${ }^{1.2,3}$ The mean parity was $6.31 \pm 2.80$, with uterovaginal prolapse being commonest among grandmultiparous women. Similarly, in other studies, genital prolapse was commonest among grandmultiparous women. ${ }^{1,2,10}$ The present study agrees with previous surveys that uterovaginal prolapse is most prevalent among post-menopausal women. ${ }^{1,2,11}$ Majority of women with genital prolapse in this study were farmers. This agrees with findings from other African studies. ${ }^{1,12}$ Grandmultiparity, post-menopausal status and farming can be explained as risk factors for uterovaginal prolapse as repeated childbirth leads to disruption of the myofascial fibers that support the pelvic organs, estrogen withdrawal weakens the integrity of the pelvic support and the physical activities involved in farming increases the intra-abdominal pressure, leading to genital prolapse.

Third-degree uterovaginal prolapse was the commonest type in this study. This was similar to findings reported by Oraekwe et al. in south-east Nigeria. ${ }^{1}$ Studies in Enugu, southeast Nigeria, Port-Harcourt, and south-south Nigeria showed contrasting findings, with second-degree uterovaginal prolapse being the most prevalent type. ${ }^{10,11}$ The disparity may be explained by difference in level of awareness and care-seeking attitude of patients in the different study settings.

In the present study, majority of women with genital prolapse did not have antenatal care during their pregnancies, there were no skilled attendants during their labors and deliveries, and they did not receive contraceptive services during their reproductive years. These findings underscore the importance of reproductive health services in preventing development of genital prolapse. Antenatal care services and presence of skilled personnel during labor and delivery can prevent conditions such as prolonged labor, obstructed labor, traumatic deliveries and perineal lacerations. These obstetric conditions are known to predispose to genital prolapse. ${ }^{5,9}$ The use of contraceptives enable women to space pregnancies and limit pregnancies to desired number. This prevents high parity which is a known predisposing factor of genital prolapse..$^{1,2,10}$

Majority of women in the present study with lower parity, higher educational level and skilled occupation such as teachers and civil servants presented earlier $(<1$ year) to the hospital. These findings suggest that women with higher socioeconomic status may be better informed of this condition and were able to overcome socioeconomic barriers against accessing medical treatment. These challenges include depending on husband or other relatives for permission and finance to seek medical treatment, and cultural and religious beliefs against orthodox medical treatments. ${ }^{13}$

There is a need for increased awareness, especially among women of lower socioeconomic status in order to improve health-seeking behavior of women with genital prolapse. There should also be a scale-up education on the importance of reproductive health services such as antenatal care services, skilled personnel, services in labor and delivery, and family planning services, as preventive tools for genital prolapse. These reproductive health services should be made available and accessible to women to reduce genital prolapse and its antecedent distressful morbidities.

\section{Conflict of Interest}

None 


\section{References}

1. Oraekwe OI, Udensi MA, Nwachukwu KC, Okali UK. Genital prolapse: A 5-year review at Federal Medical Centre Umuahia, Southeastern Nigeria. Niger. Med. J. 2016;57(5):286-289.

2. Oyiji EC, Dike El, Anolue FC, Nzewuihe ACE, Ejikem CC. Uterovaginal prolapse at a university teaching hospital in south-east Nigeria. Orient J. Med.2013;25(3-4):107-112.

3. Balogun OR. Genital prolapse in Ilorin: A seven-year review. Niger. J. Med. 1997;6:77-82.

4. Yakubu A, Abubakar Panti AA, Ladan AA, Burodo AT, Hassan MA, Nasir S. Pelvic organ prolapse managed at Usmanu Danfodiyo University Teaching Hospital, Sokoto: A 10-year review. Sahel Med. J. 2017;20:26-9.

5. Monga A, Dobbs S, editors. Gynaecology by Ten Teachers. 19th ed. London: Book Power; 2011. p. 154-62.

6. Agboola A, editor. Urogenital prolapse and the displacement of the uterus. In: Textbook of Obstetrics and Gynaecology for Medical Students. 2nd ed. Ibadan: Heinemann Educational Books PLC; 2006. p. 33-88.
7. Ogunbode O, Aimakhu VE. Uterine proplapse during pregnancy in Ibadan. Am. J. Obstet. Gynaecol. 1973;16:622-625.

8. Cespedes RO, Cross CA, MeGuire EJ. Pelvic prolapse: Diagnosing and treating uterine and vaginal vault proplapse. Medscape Women's Health 1998;3:3-4.

9. Molton PJD. Uterovaginal prolapse. In: Studd J (Ed). Progress in Obstetrics and Gynaecology, Vol. 7, Edinburgh, Churchill Livingstone, 1989:319-330.

10. Ugboma HA, Okpani AO, Anya SE. Genital prolapse in Port Harcourt, Nigeria. Niger. J. Med. 2004;13:124-9.

11. Okeke TC, Ani VC, Ezenyeaku CC, Ikeako LC, Enwereji JO, Ekwuazi K. An audit of uterovaginal prolapse in Enugu, Southeast Nigeria. Am. J. Clin. Med. Res. 2013;1:23-5.

12. Akmel M, Segni H. Pelvic organ prolapse in Jimma University specialized hospital, Southwest Ethiopia. Ethiop. J. Health Sci. 2012;22:85-92.

13. Njoku CO, Njoku AN. Obstetric fistula: The agony of unsafe motherhood. A review of Nigerian experience. JAMMR 2018; 28(12): 1-7. Article no. JAMMR 46890 .

This work is licensed under a Creative Commons Attribution-NonCommercial 3.0 Unported License which allows users to read, copy, distribute and make derivative works for non-commercial purposes from the material, as long as the author of the original work is cited properly. 